\title{
Antifungal Resistance in Isolates of Aspergillus from a Pig Farm
}

\author{
John Kerr White 1,2,3®D, Jeppe Lund Nielsen ${ }^{2}$, Jan Struckmann Poulsen ${ }^{2}$ and Anne Mette Madsen ${ }^{1, *}$ \\ 1 The National Research Centre for the Working Environment, Lersø Parkalle 105, \\ 2100 Copenhagen Ø, Denmark; john.kerr.white@ki.se \\ 2 Department of Chemistry and Bioscience, Aalborg University, Fredrik Bajers Vej 7H, \\ 9220 Aalborg Ø, Denmark; jln@bio.aau.dk (J.L.N.); jsp@bio.aau.dk (J.S.P.) \\ 3 Department of Microbiology, Tumor and Cell Biology, Division of Clinical Microbiology, Karolinska Institutet \\ and Karolinska University Hospital, 17176 Stockholm, Sweden \\ * Correspondence: amm@nrcwe.dk
}

Citation: White, J.K.; Nielsen, J.L.;

Poulsen, J.S.; Madsen, A.M.

Antifungal Resistance in Isolates of Aspergillus from a Pig Farm.

Atmosphere 2021, 12, 826. https://

doi.org/10.3390/atmos12070826

Academic Editors:

Anna Lenart-Boroń, Maria Chmiel and Ian Colbeck

Received: 1 June 2021

Accepted: 25 June 2021

Published: 28 June 2021

Publisher's Note: MDPI stays neutral with regard to jurisdictional claims in published maps and institutional affiliations.

Copyright: (C) 2021 by the authors. Licensee MDPI, Basel, Switzerland. This article is an open access article distributed under the terms and conditions of the Creative Commons Attribution (CC BY) license (https:/ / creativecommons.org/licenses/by/ $4.0 /)$.

\begin{abstract}
Antibiotic resistance in fungal isolates is increasing on a global scale. Despite knowledge that pig farmers are occupationally exposed to infectious species of fungi, such as Aspergillus spp., little is known regarding their potential exposure to antifungal-resistant Aspergillus spp. The aim of this study is to obtain knowledge regarding the antifungal resistance profiles of isolates of Aspergillus species taken from different source materials-including airborne dust, surface dust, faeces, and straw-within a pig farm. The EUCAST broth microdilution method was used for testing antifungal resistance from 43 isolates of Aspergillus sampled in 3 periods inside a Danish pig farm. Seven species of Aspergillus were obtained, including A. candidus $(n=5)$, A. fumigatus $(n=5)$, A. glaucus $(n=13)$, A. nidulans $(n=2), A$. niger $(n=15), A$. terreus $(n=1)$, and $A$. versicolor $(n=2)$. Overall, $27.9 \%$ of the Aspergillus isolates displayed resistance against at least one antifungal, and $11.6 \%$ of Aspergillus isolates displayed resistance against multiple antifungals. The most abundant group exhibiting antifungal resistance was affiliated with the species $A$. niger, with isolates exhibiting resistance to itraconazole, voriconazole, and caspofungin. One isolate of A. glaucus and two isolates of $A$. versicolor were resistant to amphotericin B (MIC $\geq 2 \mathrm{mg} / \mathrm{L}$ amphotericin B). Antibiotic-resistant fungi were found on all three sampling days.
\end{abstract}

Keywords: triazole resistance; antimycotic resistance; antimicrobial resistance; occupational health; aspergillosis; farming; dust; bioaerosols

\section{Introduction}

In certain occupational environments, such as pig farms [1] and greenhouses [2], workers are well known to be exposed to elevated concentrations of airborne particulate matter, which may contain pathogenic species of bacteria and fungi. Additionally, it has been well documented that pig farm workers are exposed to elevated concentrations of airborne, methicillin-resistant Staphylococcus aureus (MRSA) [3,4]. However, there remains less knowledge on pig farm workers' exposure to antifungal-resistant fungal species, despite the knowledge that environmental antifungal resistance is rising across Europe, with isolates from potting soil and compost displaying resistance to antifungal drugs used in human patients [5,6]. In fact, only a few occupational hygiene studies have investigated whether workers are potentially exposed to antifungal-resistant isolates $[7,8]$.

The detection of environmental isolates displaying increased resistance is of concern, as fungal infections such as invasive aspergillosis have been reported to be highly lethal in susceptible patient groups, with mortality rates between 30 and $90 \%$ [9]. Some studies have suggested that azole-naïve patients who develop azole-resistant invasive aspergillosis might acquire it from the environment [10]. In occupational settings such as pig farms, immunocompromised workers are considered to be a susceptible risk group for the development of invasive fungal infection [11]; moreover, with the increasing age 
of the population, the proportion of workers who are potentially considered susceptible will increase [12]. In Denmark, the age of farm workers is increasing, and nearly $25 \%$ of Danish farm workers are between the ages of 60 and 69 [13]. Therefore, the number of fungal infections is expected to increase in the coming years.

The acquisition of resistance to human-use antifungal drugs in environmental isolates has been proposed to be derived from the excessive use of homologous drugs against plant pathogens in agriculture, as environmental isolates and clinical isolates share similar resistance mechanisms $[10,14]$. For these reasons, people employed in industries that rely on fungicide-treated agricultural crops, including pig farms, are at risk of being exposed to antifungal-resistant fungi.

Previous research on the indoor air in pig farms has shown that workers are potentially exposed to high concentrations of airborne fungi during their work [15]. Many of the species they are exposed to are known to be pathogenic or toxin producers, and exhibit the potential to deposit deep within the airways [16]. Although workers are unlikely to develop an occupationally derived fungal lung infections-likely due to the so-called "healthy worker effect" - they are at an increased risk of developing a serious infection if they become susceptible [17].

Within the pig farms, there are multiple potential sources of airborne fungi. These include the handling of dusty materials, such as straw, which may release airborne particlesincluding fungal spores-during handling [18], and certain work tasks, such as highpressure cleaning of surfaces contaminated by faeces and settled dust, which can aerosolise microbes $[19,20]$.

The genus Aspergillus is of particular interest, as it contains several species known to be human pathogens [21] and that are known to be present in pig farms [16,22]. In particular, the species Aspergillus niger has been found on surfaces, such as soil and leaf surfaces, in occupational settings such as greenhouses $[23,24]$. Workers in physical contact with these surfaces have been observed to develop nail infections [25].

The aim of this present study was to elucidate whether environmental isolates representing seven species of Aspergillus from multiple sources in pig farms exhibit resistance to commonly used medical antifungal drugs.

\section{Materials and Methods}

\subsection{Sampling}

Sample collection occurred 3 times over a 6-week period during the months of June and July in 2019 in a stable with finishing pigs, at a high-throughput, specific pathogen-free pig farm in the region of Zealand, Denmark.

The temperature and relative humidity $(\mathrm{RH})$ were measured inside the stable during sampling using a Tinytag Plus Data Logger (Gemini Data Loggers, United Kingdom). Measurements were taken once every minute during the sampling period. The temperature varied between 15.6 and $24.2{ }^{\circ} \mathrm{C}$ and the $\mathrm{RH}$ varied between 53.9 and $69.5 \%$ over the sampling period.

Two personal gesamtstaubprobenahme (GSP) samplers mounted with polycarbonate filters (poresize $1 \mu \mathrm{m}$; CIS by BGI, Inc, Cambridge, MA, USA) with a flow rate of $3.5 \mathrm{~L} / \mathrm{min}$ were attached to a volunteer-one on each shoulder-and were used to sample inhalable airborne particles relating to a worker's personal exposure; the samples were taken at the same time as the other samples were collected. Sampling time ranged from 55 to $78 \mathrm{~min}$; the volunteer was performing activities simulating normal inspection.

eSwabs (Copan, Brescia, Italy), consisting of a flocked nylon swab in $1 \mathrm{~mL}$ of modified Amies transport medium, were used for the collection of fungi on contact surfaces and faecal matter. Samples were collected by moistening the swab head with the modified Amies transport medium prior to the collection of the material. For the collection of faecal material, the swab head was inserted into a pile of moist faecal matter and rotated. For the collection of sedimented dust, the moistened swab head was rotated axially and vertically over the dust-covered surface until the swab head was observed to be fully covered with 
dust. Locations from which dust was collected included handrails, door handles, the surface of a hose, pipes, and other fomites. A small amount of straw, approximately $10 \mathrm{~mL}$ in volume, was collected from the pigs' feed in $15 \mathrm{~mL}$ Falcon tubes. The temperature and relative humidity within the stable on each sampling day, in addition to the number of samples collected from the different source materials, are shown in Table 1.

Table 1. The number of material samples taken on each day from the airborne dust, sedimented dust, faecal matter, and straw.

\begin{tabular}{ccccc}
\hline Date & $\begin{array}{c}\text { Airborne Dust } \\
(\boldsymbol{n})\end{array}$ & $\begin{array}{c}\text { Sedimented Dust } \\
(\boldsymbol{n})\end{array}$ & Faecal Matter $(\boldsymbol{n})$ & Straw $(\boldsymbol{n})$ \\
\hline 19 June 2019 & 2 & 5 & 5 & 4 \\
\hline 3 July 2019 & 2 & 5 & 5 & 4 \\
\hline 17 July 2019 & 2 & 5 & 5 & 4 \\
\hline Total & $\mathbf{6}$ & $\mathbf{1 5}$ & $\mathbf{1 5}$ & $\mathbf{1 2}$ \\
\hline
\end{tabular}

\subsection{Extraction of Fungi from Sampled Materials}

Upon returning to the laboratory, the polycarbonate filters were removed from the GSPs, and embedded airborne particles were extracted from the filters in $5.0 \mathrm{~mL}$ of extraction fluid $(0.85 \% \mathrm{NaCl}$ and $0.05 \%$ Tween 80$)$ by shaking at $500 \mathrm{rpm}$ for $10 \mathrm{~min}$. For the extraction of particles from the straw, $7.0 \mathrm{~mL}$ of extraction fluid was added to the $15 \mathrm{~mL}$ tubes containing collected straw, which were then shaken horizontally for $15 \mathrm{~min}$. Sedimented dust and faecal samples were extracted from the eSwabs by vigorously vortexing the swabs vertically for $5 \mathrm{~min}$.

After extraction, all samples (airborne dust, sedimented dust, straw, and faecal matter) were stored and handled separately. For all sample types, $1 \mathrm{~mL}$ of extracted sample and $500 \mu \mathrm{L}$ of $87 \%$ glycerol were vortexed, and then stored at $-80{ }^{\circ} \mathrm{C}$ until processing.

\subsection{Culturing and Identification}

For the identification of fungal colony-forming units (CFUs), $200 \mu \mathrm{L}$ of thawed sample was plated on dichloran glycerol agar supplemented with chloramphenicol (DG18) (Oxoid, Hampshire, UK) in duplicate and incubated at $37^{\circ} \mathrm{C}$. Individual fungal colonies were isolated from the plate by taking a small amount of fungal material, and then sub-cultured on DG18. A small amount of the sub-cultured fungal material was transferred from the DG18 media and added to Sabouraud dextrose broth (Oxoid) for overnight incubation at room temperature in order to obtain hyphal growth with few to no spores. Isolates were then identified using matrix-assisted laser desorption/ionisation time-of-flight mass spectrometry (MALDI-TOF MS) on a microflex Biotyper system (Bruker Daltonics), using the ethanol extraction protocol [26]. Fungal isolates were identified to the species level (defined as a score > 2.0) using the Biotyper 3.1 software with the BDAL library. A bacterial test standard (BTS) (Bruker) was used to calibrate the system. Isolates were subsequently frozen at $-80^{\circ} \mathrm{C}$ until further processing. Only isolates from the genus Aspergillus were used for the antifungal resistance testing, due to the lack of breakpoints or cutoff values available for non-Candida spp. and non-Aspergillus spp. [27].

\subsection{Testing of Antifungal Resistance}

All fungal colonies from the genus Aspergillus $(n=43)$ isolated from the different sampled materials (airborne dust, settled dust, faeces, and straw) were selected for testing antifungal resistance to three classes of antimycotic drugs: triazoles (itraconazole and voriconazole; Sigma-Aldrich, Wien, Germany), an echinocandin (caspofungin acetate; Sigma-Aldrich), and a polyene (amphotericin B; Sigma-Aldrich).

The concentrations of itraconazole tested ranged from $15.6 \mu \mathrm{g} / \mathrm{L}$ to $8.0 \mathrm{mg} / \mathrm{L}$. For voriconazole, caspofungin, and amphotericin B, the tested concentrations of antifungals 
ranged from $31.25 \mu \mathrm{g} / \mathrm{L}$ to $16.0 \mathrm{mg} / \mathrm{L}$. All antifungals were dissolved in DMSO and frozen at $-80{ }^{\circ} \mathrm{C}$ until used.

We used the EUCAST broth microdilution method for conidia-forming moulds, version EDef 9.3.2, to determine the minimum inhibitory concentrations (MICs) and minimum effective concentrations (MECs) of the abovementioned antifungal agents [28]. The MIC was considered the lowest concentration that completely inhibited the growth of the strains, and the MEC was considered to be the lowest drug concentration that caused abnormal, hyphal growth. Reading of the susceptibility profiles was done visually at $48 \mathrm{~h}$ for the MIC, and via microscopy for the MEC.

In brief, isolated fungi were grown on Sabouraud dextrose agar at $37^{\circ} \mathrm{C}$ for $2-5$ days until sufficient sporulation. Spores were harvested from the media by dipping a sterile cotton swab (Selefatrade, ÖSTERSUND, Sweden) in $0.1 \%(v / v)$ Tween 20 in water, and then rubbing the swab over the spores. Spores were extracted from the swab by mixing the swab head with $5 \mathrm{~mL}$ of $0.1 \%$ Tween 20 and vigorously shaking. The spore extract was vortexed for $20 \mathrm{~s}$ before preparing a dilution series of the inoculum. The spore concentration was adjusted to a concentration between 2.0 and $5.0 \times 10^{5}$ spores $/ \mathrm{mL}$ after counting the number of spores using a haemocytometer (Reichert, Munich, Germany).

Microtiter plates containing $100 \mu \mathrm{L}$ of double-strength RPMI-1640 (ThermoFisher, Waltham, MA, USA), with 2\% glucose and MOPS buffer (Sigma Aldrich, Germany), at a $\mathrm{pH}$ of 7.0, containing the antifungals in a dilution series, were inoculated with $100 \mu \mathrm{L}$ of the spore suspension. The last two columns of the microtiter plates were used as positive and negative controls for growth and reagent sterility, respectively. These columns did not contain antifungals. For the negative controls, $100 \mu \mathrm{L}$ of sterile water from the same stock bottle used for making the final dilution was used. The inoculated microtiter plates were incubated at $37^{\circ} \mathrm{C}$ for 2 days before reading the MIC and MECs.

For the species A. fumigatus, A. terreus, and A. nidulans, isolates were defined as being antifungal resistant (R) or susceptible (S) based on the EUCAST antifungal clinical breakpoint table version 10.0 [27]. For $A$. niger and $A$. versicolor, no official $\mathrm{R}$ or $\mathrm{S}$ designations are available, but the MIC's for these species have been noted to be one twofold dilution higher than the epidemiological cutoff value (ECOFF) of $A$. fumigatus [27]. For other species $(A$. candidus and A. glaucus), breakpoints are not currently available. In addition, breakpoints are not available for caspofungin.

Once the MICs and MECs for the isolates were read, the optical density at 600nm $\left(\mathrm{OD}_{600}\right)$ was measured using an Epoch microplate spectrophotometer (BioTek, Winooski, VT, USA), with the aforementioned negative controls as blanks. An average of the $\mathrm{OD}_{600}$ $(n=2)$ for each antifungal at each dilution was used for quantifying the amount of biomass formed after $48 \mathrm{~h}$.

\subsection{Extended Resistance Testing}

Extended resistance testing was performed on a single isolate of $A$. niger with suspected paradoxical resistance using an oCelloScope system (BioSense Solutions ApS, Denmark). The aforementioned EUCAST method was used for testing antifungal resistance, with a concentration gradient of itraconazole ranging from $64 \mathrm{mg} / \mathrm{L}$ to $15.6 \mu \mathrm{g} / \mathrm{L}$, in quadruplicate. The camera focus of the oCelloScope was set to $2790 \mu \mathrm{m}$, the illumination level to 300, and the image acquisition was performed in one scan area in the centre of each well, which was scanned every 30 min for $48 \mathrm{~h}$. The growth kinetics of the strain were determined by image stack processing based on the contrast-based Segmentation Extracted Surface Area (SESA) algorithm, included in the UniExplorer software (UniExplorer, BioSense Solutions ApS).

\subsection{Data Visualisation}

All data visualisations were performed in R version 4.0.0 [29], using Rstudio version 1.3.959 [30], and the R CRAN package ggplot2 [31]. 


\section{Results}

\subsection{Fungal Species}

A total of 43 Aspergillus isolates were cultured from settled dust, faecal matter, straw material, and airborne dust samples, from an overall total of 354 isolates of fungi grown at $37^{\circ} \mathrm{C}$. Other fungi cultured included members of the genera Candida, Lichtheimia, Rhizomucor, Trichosporon, and Scopulariopsis.

Species of Aspergillus cultured were identified as A. candidus, A. fumigatus, A. glaucus, A. nidulans, A. niger, A. terreus, and A. versicolor. The most diverse source material was the settled dust (five species), followed by the straw (four species), airborne dust (three species), and faecal matter (one species), as shown in Figure 1. Faecal matter, settled dust, and straw samples taken on 19 June contained $A$. candidus, A. fumigatus, A. nidulans, and $A$. versicolor. From the samples taken on $3 \mathrm{July}, A$. candidus, A. glaucus, and A. versicolor were cultured from the settled dust and straw. From the samples taken on $17 \mathrm{July}, A$. candidus, $A$. fumigatus, A. glaucus, A. nidulans, A. niger, and A. terreus were cultured from the airborne dust, settled dust, faecal matter, and/or straw (Supplementary Figure S1).

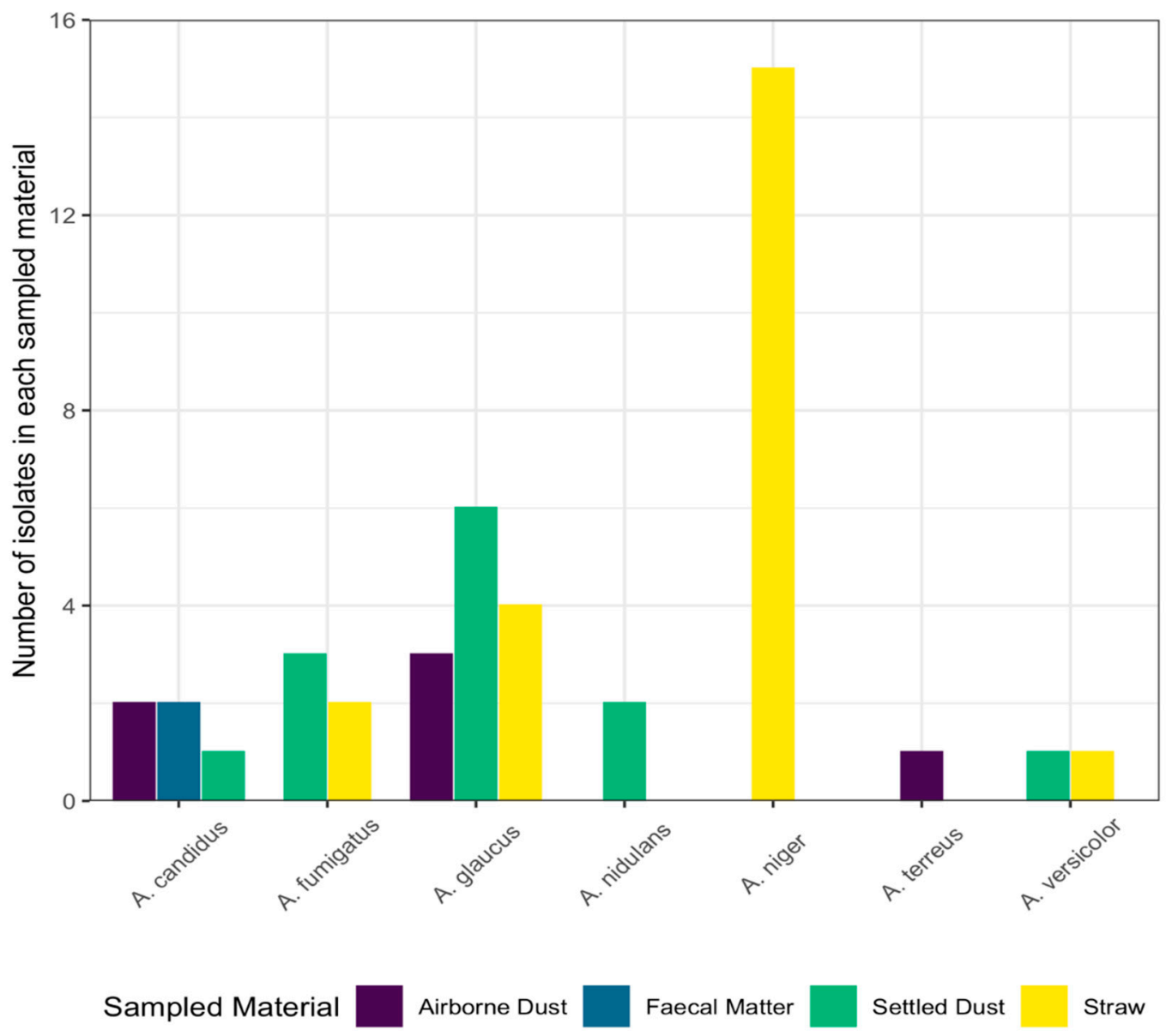

Figure 1. Species and number of Aspergillus isolates cultured from four sampling materials are shown on the x-and y-axes, respectively. Each bar is coloured to represent the material the isolates were collected from: purple: airborne dust $(n=6)$; blue: faecal matter $(n=15)$; green: settled dust $(n=15)$; yellow: straw $(n=12)$.

\subsection{Resistance Profiles}

Resistance to all of the tested antifungals was found, with $27.9 \%$ of the isolates displaying resistance against at least one antifungal, and $11.6 \%$ of isolates displaying resistance against multiple antifungals. 
The species $A$. niger showed the greatest amount of antifungal resistance amongst the 7 species of Aspergillus found in this study, with 10/43 (23.3\%) isolates exhibiting resistance to itraconazole, voriconazole, and caspofungin. A. terreus and A. versicolor both exhibited resistance to amphotericin B, as shown in Figure 2, as their MIC values exceeded the clinical breakpoints.
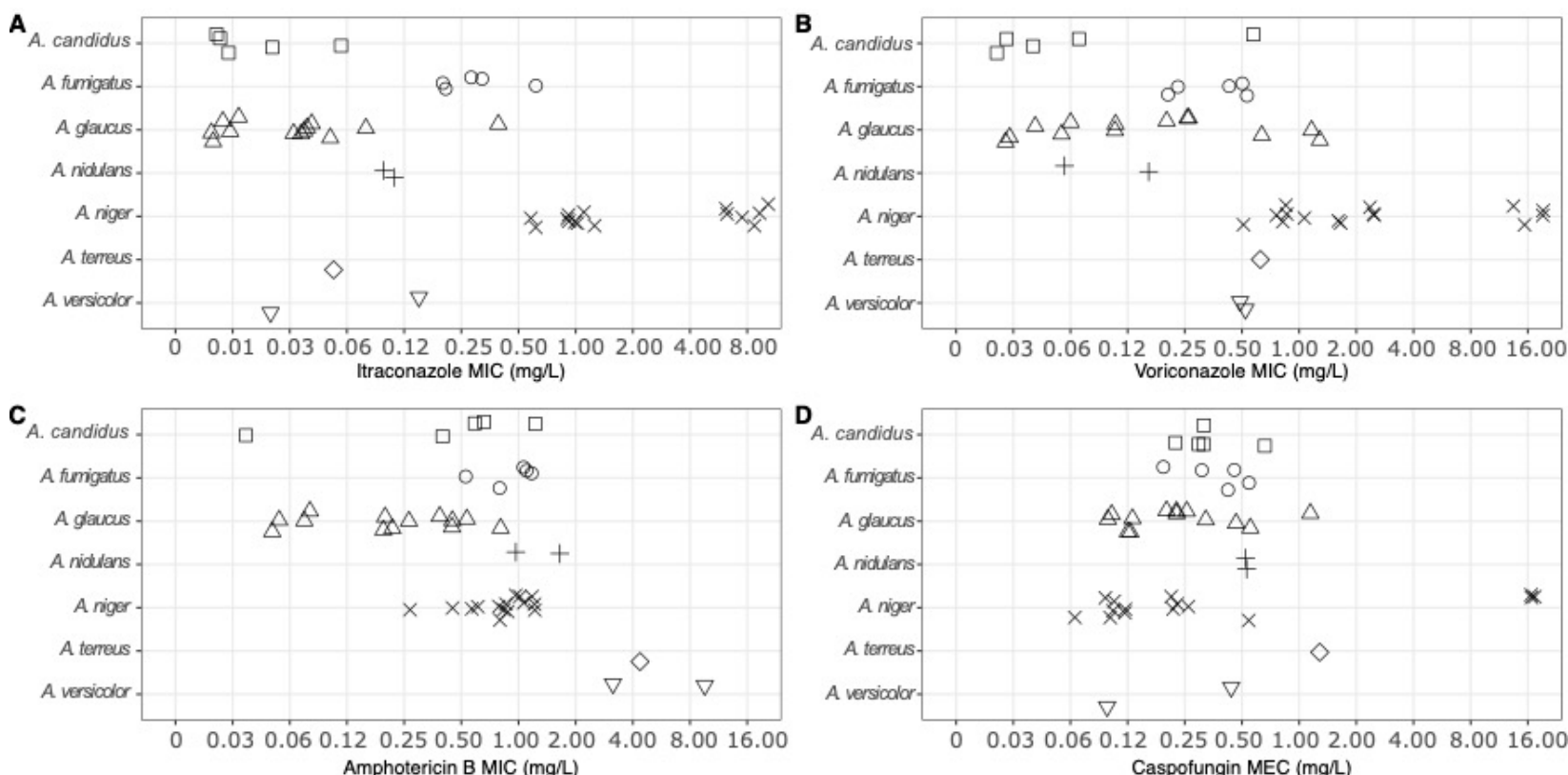

Figure 2. The minimum inhibitory concentration (MIC) and minimum effective concentration (MEC) of each Aspergillus isolate $(n=43)$ tested against $(\mathbf{A})$ itraconazole, $(\mathbf{B})$ voriconazole, $(\mathbf{C})$ amphotericin B, and (D) caspofungin. Each point represents an individual isolate's MIC or MEC to the tested antifungal. The different symbols represent the different species of Aspergillus (squares: A. candidus; circles: A. fumigatus; triangles: A. glaucus; crosses: A. nidulans; crosses: A. niger; diamonds: A. terreus; inverted triangles: $A$. versicolor).

Six isolates of $A$. niger were resistant to itraconazole (MIC $\geq 2 \mathrm{mg} / \mathrm{L}$ itraconazole) and nine were resistant to voriconazole (MIC $\geq 2 \mathrm{mg} / \mathrm{L}$ voriconazole). One isolate of $A$. glaucus and two isolates of $A$. versicolor had elevated MICs to amphotericin B (MIC $\geq 2 \mathrm{mg} / \mathrm{L}$ amphotericin B), while three isolates of $A$. niger had high MECs to caspofungin (MEC $\geq 16 \mathrm{mg} / \mathrm{L}$ caspofungin). Three isolates of $A$. niger exhibited multidrug resistance toward itraconazole, voriconazole, and caspofungin (Figure 2), as their MIC and MEC values were above the ECOFF for $A$. fumigatus.

\subsection{Potential Paradoxical Resistance}

Six isolates of $A$. niger ( $n=15$ ) exhibited signs of paradoxical resistance to itraconazole, as they showed spontaneous recovery of growth at increasing concentrations of antifungal. This effect is shown in Figure $3 \mathrm{~A}$, where $\mathrm{OD}_{600}$ measurements show that growth spontaneously began at concentrations above the clinical breakpoint ( $2 \mathrm{mg} / \mathrm{L}$ of itraconazole).

One of the six isolates of $A$. niger was analysed for growth at extended concentrations of itraconazole using the oCelloScope system. In this isolate, it was found that further increases in itraconazole resulted in decreased growth (Figure 3B). 

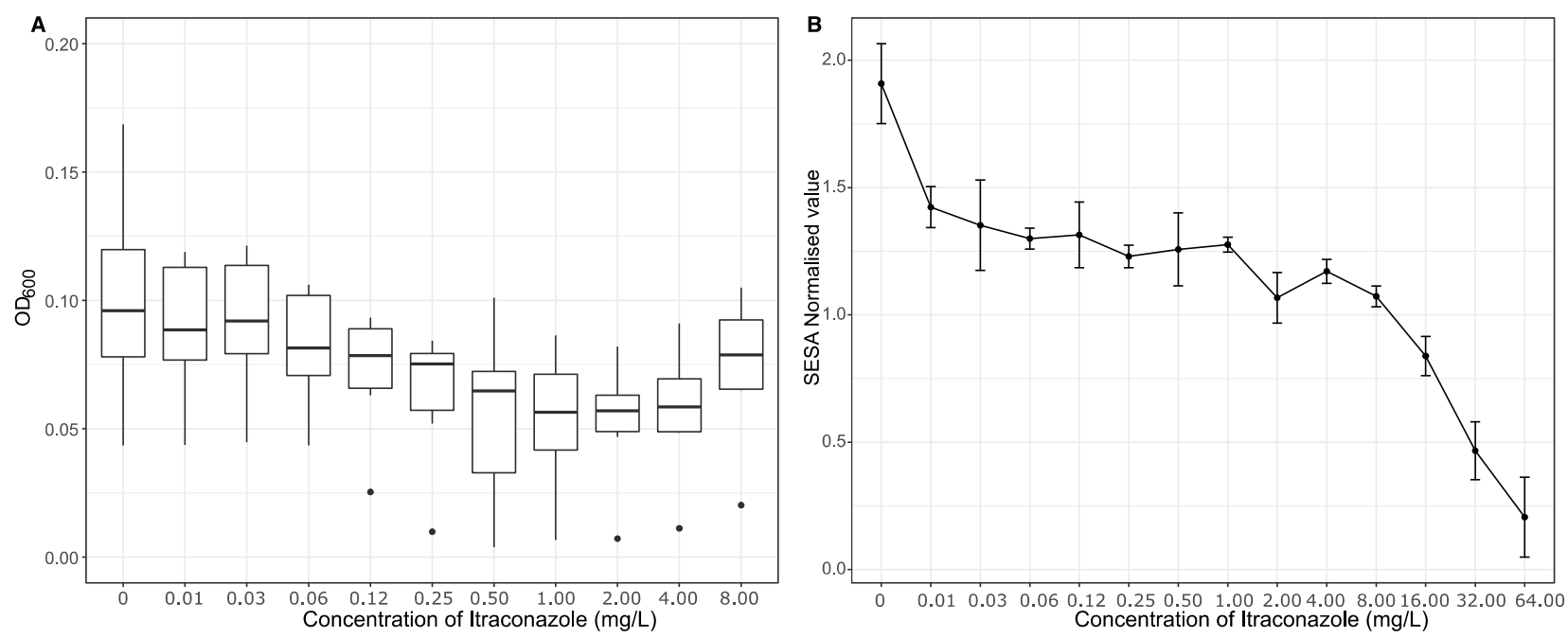

Figure 3. (A) The average optical density $\left(\mathrm{OD}_{600}\right)$ showing the amount of growth from six isolates of Aspergillus niger potentially displaying paradoxical resistance. The $\mathrm{OD}_{600}$ was read after two days of incubation with varying concentrations $(0-8.0 \mathrm{mg} / \mathrm{L})$ of itraconazole. The boxplots bound the interquartile range (IQR) divided by the median; the whiskers extend to $1.5 \times$ IQR beyond the box. Single points are used to indicate potential outliers. (B) Segmentation Extraction Surface Area (SESA)-normalised values measured after $48 \mathrm{~h}$, showing the biomass produced by a single isolate of Aspergillus niger challenged with concentrations of itraconazole ranging from 0 to $64.0 \mathrm{mg} / \mathrm{L}$.

\section{Discussion}

Globally, the number of clinical isolates of Aspergillus that are resistant to medical antifungal drugs is increasing [32]. This is of great concern, as an estimated 200,000 people die each year from invasive aspergillosis [9]. Despite the knowledge that antifungal resistance is increasing in clinical and agricultural settings, and that pig farm workers are exposed to elevated concentrations of fungi and may be sources of antibiotic-resistant microorganisms, environmental isolates of Aspergillus species from pig farms have not been well studied for resistance profiles.

In this study, both airborne and non-airborne fungi were resistant to antifungals, and were detected on all sampling days. Thus, antifungal-resistant isolates were found in the collected faecal matter, sedimented dust, and straw, in addition to the air samples. This is of concern, as workers in stables may inhale the airborne dust and, furthermore, high-pressure cleaning of surfaces-such as those contaminated by faeces and settled dust - can aerosolise microbes [19], while straw can release airborne particles, including spores, during handling [18]. A previous study on the microbial context of settling dust has shown that a significant fraction of the bacterial and fungal species are associated with the gastrointestinal tracts of pigs [33]. Therefore, a large proportion of the bioaerosols in pig stables are likely derived from the pigs' faecal matter. In addition to the potential of the microbes to become airborne, handling of materials containing pathogenic fungi-such as $A$. niger - has been shown to lead to the development of occupationally derived nail infections [25]. During our study, we collected a total of over 300 isolates of pathogenic fungi consisting of the genera Aspergillus, Candida, Lichtheimia, Rhizomucor, Trichosporon, and Scopulariopsis, all of which contained species that are known human pathogens, or emerging pathogens [21]. An overview of the number of isolates from each genus collected on the three sampling days is shown in Supplementary Figure S2. Of these genera, we focused on the antifungal resistance within the genus Aspergillus, and found that over $25 \%$ of our tested isolates were resistant to at least one antifungal.

The species Aspergillus fumigatus is the most common aetiological agent of aspergillosis worldwide [9]. In this study, we only detected five isolates of this species, none of which were resistant to itraconazole, voriconazole, amphotericin $\mathrm{B}$, or caspofungin. Other recent environmental survey studies have detected antifungal resistance in A. fumigatus [5,8]. 
In contrast, the species $A$. niger was found in greater numbers, and several isolates from this species were resistant to multiple classes of the antifungals tested. The presence of multidrug-resistant $A$. niger should be of concern, as although invasive disease caused by A. niger is less commonly described, it is a known human pathogen, and can cause invasive aspergillosis [21,34]. In addition, inhalation of spores from $A$. niger has been known to induce hypersensitivity pneumonitis [35], and the spores from A. niger have been shown to be cytotoxic [36].

In our study, we detected one isolate of $A$. terreus isolated from airborne dust, and two isolates of $A$. versicolor, which were collected from the settled dust and from the straw. Both of these species are known human pathogens [21], and the presence of airborne $A$. terreus may be of concern, as lung infections with $A$. terreus are associated with poor clinical outcomes for susceptible patients [37].

Although infections caused by Aspergillus are rare in immunocompetent patients, previous studies have shown that workers are at an increased risk of developing airway maladies due to exposure to Aspergillus spp. In a study from Germany, compost waste workers exposed to fungal bioaerosols developed occupationally derived allergic bronchopulmonary aspergillosis (ABPA), which was treated with corticosteroids and itraconazole [38]. However, if workers are exposed to-and develop an infection from-multidrugresistant microorganisms, such as Aspergillus spp., then normal treatment using first-line antifungals - including itraconazole - may not be sufficient to clear the infection [39].

In this study, the sampled material with the greatest number of Aspergillus isolates was the straw, which was also the only sampled material from which $A$. niger was identified. Other studies have found $A$. niger in airborne dust particles from pig farms [16,22]. However, this study was performed sampling a smaller volume of air than the other studies, and it is therefore possible that airborne spores or hyphal fragments of $A$. niger were present in the pig farm, but were simply not collected in our samples. Although no isolates of A. niger were detected in airborne dust samples, previous research has shown that straw containing fungi can release fungal spores during handling [18]. This thereby presents an occupational health risk for pig farm workers, as they might develop aspergillosis after inhaling airborne spores, or develop nail infections after handling the straw.

It should be noted that, according to the guidelines provided by the EUCAST antifungal clinical breakpoint table, there is insufficient evidence for an official EUCAST "resistant" or "susceptible" classification when using echinocandins against Aspergillus spp. However, although the EUCAST official guidelines do not give an official resistant or susceptible classification, in this study, it appears that that three of our isolates of $A$. niger can be referred to as being caspofungin-resistant, as their resistance to caspofungin was at the upper limit of the assay (MEC $>16 \mathrm{mg} / \mathrm{L}$ caspofungin).

Of the research done regarding occupational exposure to fungi, most has focused on potential respiratory deposition [16], microbial community composition [33,40], or mycotoxin contents [41]. While all of these aspects are important with regards to the development of an accurate occupational risk assessment, they do not consider antifungal resistance. Therefore, the results from this study are of importance, as they are the first results showing the antifungal resistance patterns of Aspergillus spp. isolated from a pig farm. Previous research studying antifungal resistance in other occupational settings has focused on resistance to triazoles (itraconazole, posaconazole, and voriconazole) $[7,8]$. These studies have shown that triazole resistance is widespread, and that a variety of different species-including members of Aspergillus, Alternaria, Cladosporium, Chrysosporium, Penicillium, and Rhizomucor-are able to grow in triazole-spiked media. In our study, we calculated the individual MICs and MECs of our Aspergillus isolates to triazoles and, in addition, to two other classes of antifungals (polyenes and echinocandins), and were able to show that isolates of $A$. niger are resistant to multiple classes of antifungals. This is of concern, as multidrug resistance in pathogenic species is associated with increases in mortality [42]. 
Fungal isolates that might normally be considered susceptible to antifungals can counterintuitively exhibit in vitro growth in a range of higher concentrations of antifungals. This has been referred to as the "Eagle effect" or "paradoxical resistance", and is defined as an isolate being able to grow in low concentrations of antifungal, being growth-inhibited at intermediate concentrations, and resuming growth at higher concentrations [43]. In addition to the antifungal-resistant species and isolates of fungi identified, we observed six isolates of $A$. niger that, although they were antifungal-susceptible, exhibited signs of paradoxical resistance to itraconazole (Figure 3A); this phenomenon has only once been previously described amongst Aspergillus section Nigri [44]. Most research regarding paradoxical resistance amongst Aspergillus and Candida has been associated with echinocandins $[45,46]$. Of the research that has been conducted for elucidating the paradoxical resistance mechanisms against echinocandins, these studies have proposed that there is an upregulation of cell wall chitin synthesis [47]. With regards to paradoxical resistance amongst aspergilli to triazoles, no mechanisms have been proposed. However, a proteomic approach involving differential protein expression during incubation with and without triazoles could elucidate which molecular pathways are up- or downregulated in isolates displaying paradoxical resistance.

Further analysis regarding one of the potentially paradoxically resistant isolates of $A$. niger showed that although there was an increase in growth after the "normal" breakpoint when the $\mathrm{OD}_{600}$ was measured (Figure $3 \mathrm{~A}$ ), there was a marked decrease in growth when the isolate was challenged with concentrations of itraconazole far exceeding the normal breakpoint when growth was measured using the oCelloScope assay (Figure 3B). Further research is required for these isolates, in order to determine whether they are actually paradoxically resistant, and which molecular mechanisms might be involved. A recent study analysing the proteome of one of the potentially paradoxical $A$. niger isolates taken during the present sampling period showed significant changes in ergosterol synthesis, efflux transporters, and reduced expression of peroxidative enzymes [48].

Overall, this study demonstrates that environmental isolates, assumed to be medically antifungal-naïve, exhibit classical and possibly also paradoxical resistance, similar to what has been found in clinical samples taken from patients. This study provides evidence for the presence of antifungal-resistant Aspergillus spp. from multiple sources within a pig farm. While pig farming might not directly contribute to the increase in the number of isolates that display antifungal resistance, workers exposed to high concentrations of fungi might have a greater risk of developing an antifungal-resistant fungal infection.

\section{Conclusions}

Antifungal-resistant fungi were present on surfaces and in the air in a pig farm during all three sampling days. Multiple isolates of the most commonly identified species- $A$. niger - presented with multidrug resistance to three of the four tested antifungals. This is notable, as it may cause occupational fungal infections to increase. Furthermore, A. niger may be transported away from the farm, where it can potentially cause lethal invasive disease in susceptible patient groups. Isolates of $A$. terreus and $A$. versicolor also exhibited resistance to amphotericin $B$. Therefore, in order to make an accurate occupational risk assessment, occupational hygienists should be encouraged to test for antifungal resistance amongst their samples, first of all to test workers' potential exposure to antifungal-resistant fungi, but also to help monitor the global spread of antifungal resistance in agricultural, non-agricultural, and non-medical settings.

Supplementary Materials: The following are available online at https://www.mdpi.com/article/ 10.3390/atmos12070826/s1, Figure S1: Species and number of Aspergillus isolates cultured from the four sampled materials (purple $=$ airborne dust, blue $=$ faeces, green $=$ settled dust, and yellow = straw). The sampling day is written on the top of each plot. Figure S2: Species and number of fungal isolates from the genera Aspergillus, Candida, Lichtheimia, Rhizomucor, Scopulariopsis, and Trichosporon cultured from the four sampled materials (purple $=$ airborne dust, blue $=$ faeces, green $=$ settled dust, and yellow $=$ straw). The sampling day is written on the top of each plot. 
Author Contributions: J.K.W.: Conceptualisation, formal analysis, investigation, methodology, visualisation, writing —original draft, writing—review and editing; J.L.N.: funding acquisition, project administration, supervision, resources, writing-review and editing; J.S.P.: formal analysis, methodology; A.M.M.: funding acquisition, project administration, supervision, writing-review and editing. All authors have read and agreed to the published version of the manuscript.

Funding: This study was funded by the National Research Centre for the Working Environment, Copenhagen, Denmark, and Aalborg University, Denmark.

Institutional Review Board Statement: Not applicable.

Informed Consent Statement: Not applicable.

Data Availability Statement: Not applicable.

Acknowledgments: The authors would like to thank Carla Viegas for providing the antifungalresistant strains of $A$. fumigatus that were used in this study. In addition, the authors would like to thank the farmers for opening their doors to us. This study was supported by the National Research Centre for the Working Environment, the Danish Working Authority, and Aalborg University.

Conflicts of Interest: The authors declare no conflict of interest.

\section{References}

1. Angen, Ø.; Feld, L.; Larsen, J.; Rostgaard, K.; Skov, R.; Madsen, A.M.; Larsen, A.R. Transmission of methicillin-resistant Staphylococcus aureus to human volunteers visiting a swine farm. Appl. Environ. Microbiol. 2017, 83. [CrossRef]

2. Madsen, A.M.; White, J.K.; Markouch, A.; Kadhim, S.; de Jonge, N.; Thilsing, T.; Hansen, V.M.; Bælum, J.; Nielsen, J.L.; Vogel, U.; et al. A cohort study of cucumber greenhouse workers' exposure to microorganisms as measured using NGS and MALDI-TOF MS and biomarkers of systemic inflammation. Environ. Res. 2021, 192. [CrossRef] [PubMed]

3. Garcia-Graells, C.; Antoine, J.; Larsen, J.; Catry, B.; Skov, R.; Denis, O. Livestock veterinarians at high risk of acquiring methicillinresistant Staphylococcus aureus ST398. Epidemiol. Infect. 2012, 140, 383-389. [CrossRef]

4. Masclaux, F.G.; Sakwinska, O.; Charriere, N.; Semaani, E.; Oppliger, A. Concentration of airborne Staphylococcus aureus (MRSA and MSSA), total bacteria, and endotoxins in pig farms. Ann. Occup. Hyg. 2013, 57, 550-557. [CrossRef]

5. Mortensen, K.L.; Mellado, E.; Lass-Flörl, C.; Rodriguez-Tudela, J.L.; Johansen, H.K.; Arendrup, M.C. Environmental study of azole-resistant Aspergillus fumigatus and other aspergilli in Austria, Denmark, and Spain. Antimicrob. Agents Chemother. 2010, 54, 4545-4549. [CrossRef]

6. Prigitano, A.; Esposto, M.C.; Romanò, L.; Auxilia, F.; Tortorano, A.M. Azole-resistant Aspergillus fumigatus in the Italian environment. J. Glob. Antimicrob. Resist. 2019, 16, 220-224. [CrossRef]

7. Caetano, L.A.; Faria, T.; Springer, J.; Loeffler, J.; Viegas, C. Antifungal-resistant Mucorales in different indoor environments. Mycology 2019, 10, 75-83. [CrossRef] [PubMed]

8. Viegas, C.; Almeida, B.; Aranha Caetano, L.; Afanou, A.; Straumfors, A.; Veríssimo, C.; Gonçalves, P.; Sabino, R. Algorithm to assess the presence of Aspergillus fumigatus resistant strains: The case of Norwegian sawmills. Int. J. Environ. Health Res. 2020, 1-9. [CrossRef] [PubMed]

9. Brown, G.D.; Denning, D.W.; Gow, N.A.R.; Levitz, S.M.; Netea, M.G.; White, T.C. Hidden killers: Human fungal infections. Sci. Transl. Med. 2012, 4. [CrossRef]

10. Snelders, E.; Huis in 't Veld, R.A.G.; Rijs, A.J.M.M.; Kema, G.H.J.; Melchers, W.J.G.; Verweij, P.E. Possible Environmental Origin of Resistance of Aspergillus fumigatus to Medical Triazoles. Appl. Environ. Microbiol. 2009, 75, 4053-4057. [CrossRef] [PubMed]

11. Khasawneh, F.; Mohamad, T.; Moughrabieh, M.K.; Lai, Z.; Ager, J.; Soubani, A.O. Isolation of Aspergillus in critically ill patients: A potential marker of poor outcome. J. Crit. Care 2006, 21, 322-327. [CrossRef]

12. Kashyap, B.; Das, S.; Sagar, T.; Gupta, K. Current Scenario of Geriatric Fungal Infections: A Prevalence Study from a Tertiary Care Hospital. J. Indian Acad. Geriatr. 2017, 13, 1-6. [CrossRef]

13. Danmarks Statistik Kun få Unge Landmænd i Danmark. Available online: https://www.dst.dk/da/Statistik/nyt/NytHtml? cid=25859 (accessed on 7 October 2020).

14. Azevedo, M.-M.; Faria-Ramos, I.; Cruz, L.C.; Pina-Vaz, C.; Gonçalves Rodrigues, A. Genesis of Azole Antifungal Resistance from Agriculture to Clinical Settings. J. Agric. Food Chem. 2015, 63, 7463-7468. [CrossRef]

15. Sowiak, M.; Bródka, K.; Buczyńska, A.; Cyprowski, M.; Kozajda, A.; Sobala, W.; Szadkowska-Stańczyk, I. An assessment of potential exposure to bioaerosols among swine farm workers with particular reference to airborne microorganisms in the respirable fraction under various breeding conditions. Aerobiologia 2011, 28, 121-133. [CrossRef]

16. White, J.K.; Nielsen, J.L.; Madsen, A.M. Potential Respiratory Deposition and Species Composition of Airborne Culturable, Viable, and Non-Viable Fungi during Occupancy in a Pig Farm. Atmosphere 2020, 11, 639. [CrossRef]

17. Park, S.J.; Mehrad, B. Innate immunity to Aspergillus species. Clin. Microbiol. Rev. 2009, 22, 535-551. [CrossRef] [PubMed]

18. Madsen, A.M.; Kruse, P.; Schneider, T. Characterization of Microbial Particle Release from Biomass and Building Material Surfaces for Inhalation Exposure Risk Assessment. Ann. Occup. Hyg. 2005, 50, 175-187. [CrossRef] 
19. Braymen, D.T. Survival of Micro-Organisms in Aerosols Produced in Cleaning and Disinfecting. Public Heal. Rep. 1969, 84, 547-552. [CrossRef]

20. Madsen, A.M.; Matthiesen, C.B. Exposure to aerosols during high-pressure cleaning and relationship with health effects. Ann. Agric. Environ. Med. 2013, 20, 420-425. [PubMed]

21. Ausschuss für Biologische Arbeitsstoffe. Technische Regeln für Biologische Arbeitsstoffe: Einstufung von Pilzen in Risikogruppen. Available online: https://www.baua.de/DE/Angebote/Rechtstexte-und-Technische-Regeln/Regelwerk/TRBA/TRBA-460.html (accessed on 28 June 2021).

22. Sabino, R.; Faísca, V.M.; Carolino, E.; Veríssimo, C.; Viegas, C. Occupational Exposure to Aspergillus by Swine and Poultry Farm Workers in Portugal. J. Toxicol. Environ. Health Part A 2012, 75, 1381-1391. [CrossRef]

23. Hamaguchi, R.; Saito, H.; Kegasawa, K.; Nakagawa, A.; Ryujin, Y.; Noguchi, S.; Sugimoto, H.; Kobayashi, A.; Yamazaki, K.; Jin, Y.; et al. A case of hypersensitivity pneumonitis resulting from inhalation of Aspergillus niger in a greenhouse worker who raised roses. Nihon Kokyuki Gakkai Zasshi 2009, 47, 205-211.

24. Punja, Z.K.; Collyer, D.; Scott, C.; Lung, S.; Holmes, J.; Sutton, D. Pathogens and Molds Affecting Production and Quality of Cannabis sativa L. Front. Plant Sci. 2019, 10, 1-23. [CrossRef]

25. Bongomin, F.; Batac, C.R.; Richardson, M.D.; Denning, D.W. A Review of Onychomycosis Due to Aspergillus Species. Mycopathologia 2018, 183, 485-493. [CrossRef]

26. Madsen, A.M.; Zervas, A.; Tendal, K.; Nielsen, J.L. Microbial diversity in bioaerosol samples causing ODTS compared to reference bioaerosol samples as measured using Illumina sequencing and MALDI-TOF. Environ. Res. 2015, 140, 255-267. [CrossRef]

27. Arendrup, M.C.; Friberg, N.; Mares, M.; Kahlmeter, G.; Meletiadis, J.; Guinea, J.; Arendrup, M.C.; Meletiadis, J.; Guinea, J.; Friberg, N.; et al. How to interpret MICs of antifungal compounds according to the revised clinical breakpoints v. 10.0 European committee on antimicrobial susceptibility testing (EUCAST). Clin. Microbiol. Infect. 2020. [CrossRef]

28. Arendrup, M.C.; Meletiadis, J.; Mouton, J.W.; Lagrous, K.; Hamal, P.; Guinea, J. Subcommittee on Antifungal Susceptibility Testing (AFST) of the ESCMID European Committee for Antimicrobial Susceptibility Testing (EUCAST). Method for the Determination of Broth Dilution Minimum Inhibitory Concentrations of Antifungal Agents for Conidia Forming Moulds Version 9.3.2. Available online: https://www.eucast.org/fileadmin/src/media/PDFs /EUCAST_files/AFST/Files/EUCAST_E_Def_9.3.2_ Mould_testing_definitive_revised_2020.pdf (accessed on 28 June 2021).

29. Team, R.C. R: A Language and Environment for Statistical Computing; R Foundation for Statistical Computing: Vienna, Austria, 2015.

30. RSudio Team. RStudio: Integrated Development Environment for R. Available online: https://www.rstudio.com/categories/ integrated-development-environment/ (accessed on 28 June 2021).

31. Wickham, H. ggplot2: Elegant Graphics for Data Analysis; Springer: New York, NY, USA, 2016; ISBN 978-3-319-24277-4.

32. Vermeulen, E.; Lagrou, K.; Verweij, P.E. Azole resistance in Aspergillus fumigatus: A growing public health concern. Curr. Opin. Infect. Dis. 2013, 26, 493-500. [CrossRef] [PubMed]

33. White, J.K.; Nielsen, J.L.; Madsen, A.M. Microbial species and biodiversity in settling dust within and between pig farms. Environ. Res. 2019, 171. [CrossRef]

34. Person, A.K.; Chudgar, S.M.; Norton, B.L.; Tong, B.C.; Stout, J.E. Aspergillus niger: An unusual cause of invasive pulmonary aspergillosis. J. Med. Microbiol. 2010, 59, 834-838. [CrossRef] [PubMed]

35. Sakamoto, T.; Yamasaki, A.; Funaki, Y.; Harada, T.; Okazaki, R.; Hasegawa, Y.; Sueda, Y.; Fukushima, T.; Morita, M.; Yamamoto, A.; et al. An onion farmer with a case of hypersensitivity pneumonitis caused by Aspergillus niger. Respir. Med. Case Rep. 2018, 23, 60-62. [CrossRef]

36. Lu, R.; Tendal, K.; Frederiksen, M.W.; Uhrbrand, K.; Li, Y.; Madsen, A.M. Strong variance in the inflammatory and cytotoxic potentials of Penicillium and Aspergillus species from cleaning workers' exposure in nursing homes. Sci. Total Environ. 2020, 724, 138231. [CrossRef] [PubMed]

37. Iwen, P.C.; Rupp, M.E.; Langnas, A.N.; Reed, E.C.; Hinrichs, S.H. Invasive Pulmonary Aspergillosis Due to Aspergillus terreus: 12-Year Experience and Review of the Literature. Clin. Infect. Dis. 1998, 26, 1092-1097. [CrossRef]

38. Poole, C.J.M.; Wong, M. Allergic bronchopulmonary aspergillosis in garden waste (compost) collectors-occupational implications. Occup. Med. (Chic. Ill). 2013, 63, 517-519. [CrossRef]

39. Friedman, N.D.; Temkin, E.; Carmeli, Y. The negative impact of antibiotic resistance. Clin. Microbiol. Infect. 2016, $22,416-422$. [CrossRef]

40. Kristiansen, A.; Saunders, A.M.; Hansen, A.A.; Nielsen, P.H.; Nielsen, J.L. Community structure of bacteria and fungi in aerosols of a pig confinement building. FEMS Microbiol. Ecol. 2012, 80, 390-401. [CrossRef]

41. Viegas, C.; Carolino, E.; Sabino, R.; Viegas, S.; Veríssimo, C. Fungal Contamination in Swine: A Potential Occupational Health Threat. J. Toxicol. Environ. Heal. Part A 2013, 76, 272-280. [CrossRef] [PubMed]

42. Cosgrove, S.E. The Relationship between Antimicrobial Resistance and Patient Outcomes: Mortality, Length of Hospital Stay, and Health Care Costs. Clin. Infect. Dis. 2006, 42, S82-S89. [CrossRef] [PubMed]

43. Prasetyoputri, A.; Jarrad, A.M.; Cooper, M.A.; Blaskovich, M.A.T. The Eagle Effect and Antibiotic-Induced Persistence: Two Sides of the Same Coin? Trends Microbiol. 2019, 27, 339-354. [CrossRef]

44. Alcazar-Fuoli, L.; Mellado, E.; Alastruey-Izquierdo, A.; Cuenca-Estrella, M.; Rodriguez-Tudela, J.L. Species Identification and Antifungal Susceptibility Patterns of Species Belonging to Aspergillus Section Nigri. Antimicrob. Agents Chemother. 2009, 53, 4514-4517. [CrossRef] 
45. Loiko, V.; Wagener, J. The Paradoxical Effect of Echinocandins in Aspergillus fumigatus Relies on Recovery of the $\beta-1,3-G l u c a n$ Synthase Fks1. Antimicrob. Agents Chemother. 2017, 61, 1-11. [CrossRef] [PubMed]

46. Wagener, J.; Loiko, V. Recent insights into the paradoxical effect of echinocandins. J. Fungi 2018, 4, 5. [CrossRef] [PubMed]

47. Stevens, D.A.; Ichinomiya, M.; Koshi, Y.; Horiuchi, H. Escape of Candida from Caspofungin Inhibition at Concentrations above the MIC (Paradoxical Effect) Accomplished by Increased Cell Wall Chitin; Evidence for $\beta-1,6-G l u c a n$ Synthesis Inhibition by Caspofungin. Antimicrob. Agents Chemother. 2006, 50, 3160-3161. [CrossRef] [PubMed]

48. Poulsen, J.S.; Madsen, A.M.; White, J.K.; Nielsen, J.L. Physiological Responses of Aspergillus niger Challenged with Itraconazole. Antimicrob. Agents Chemother. 2021, 65. [CrossRef] [PubMed] 